\title{
Pemanfaatan Bentonite sebagai Media Pembumian Elektroda Batang
}

\author{
Winanda Riga Tamma, I Made Yulistya Negara, dan Daniar Fahmi \\ Jurusan Teknik Elektro, Fakultas Teknologi Industri, Institut Teknologi Sepuluh Nopember \\ (ITS) Jl. Arief Rahman Hakim, Surabaya 60111 \\ E-mail: yulistya@ee.its.ac.id, daniarfahmi.elits@gmail.com
}

\begin{abstract}
Abstrak- Sistem pentanahan merupakan suatu sistem yang bertujuan untuk mengamankan sistem tenaga listrik dari gangguan ke tanah maupun gangguan hubung singkat. Pada sistem pentanahan yang baik, resistansi pentanahan harus bernilai dibawah lima ohm. Resistansi pentanahan bergantung pada berbagai aspek antara lain yaitu struktur tanah, kelembapan tanah, dan kandungan yang ada dalam tanah itu sendiri. Dalam pengujian pada penelitian ini akan dilakukan perbaikan pada tanah dengan mencampurkan bentonite ke dalam tanah sebagai media pentanahan. Pencampuran bentonite bertujuan agar mendapatkan nilai resistansi pentanahan yang baik sesuai dengan standar sistem pentanahan. Pengujian dilakukan menggunakan elektroda batang dan alat earth resistance tester dengan metode tiga titik dimana elektroda utama atau elektroda pengukuran diberikan treatment sesuai dengan kondisi yang telah ditentukan. Diharapkan pada pengujian ini akan diketahui dampak dari bentonite terhadap penurunan nilai resistansi pentanahan. Hasil pengujian menunjukkan bahwa dengan mencampurkan bentonite pada media pentanahan, resistansi pentanahan menjadi lebih baik. Meskipun tidak terlalu signifikan, rata-rata penurunan dari setiap masing-masing treatment adalah sebesar $2 \mathrm{ohm}$.
\end{abstract}

Kata Kunci-Bentonite, Nilai Resistansi Pentanahan Sistem Pentanahan.

\section{PENDAHULUAN}

SUATU sistem distribusi tenaga listrik merupakan sistem Nyang luas yang menghubungkan satu titik ke titik lain sehingga sangat peka terhadap berbagai gangguan, diantaranya adalah gangguan tanah[1]. Gangguan tersebut memiliki banyak dampak yang dapat mengurangi kestabilan sistem tenaga listrik dan membahayakan perlatan serta manusia. Sistem pembumian (grounding system) adalah suatu perangkat instalasi yang berfungsi untuk melepaskan arus petir atau arus gangguan ke dalam bumi. Salah satu faktor yang berpengaruh agar kestabilan sistem dan keamanan peralatan listrik tetap terjaga adalah dengan sistem pentanahan pada peralatan yang baik [2]. Sistem grounding yang baik harus bisa mendapatkan nilai tahanan sebaran maksimal 5 (lima) ohm diukur dengan menggunakan earth resistance tester [3]. Nilai resistansi pentanahan dipengaruhi oleh kandungan dan unsur tanah yang digunakan [4]. Mengacu pada penelitian sebelumnya yang telah dilakukan untuk mengurangi resistansi pada tanah menggunakan bentonite sebagai media pentanahan elektroda jenis batang, metode tersebut mampu mengurangi resistansi tanah seminim mungkin [5].
Untuk mengetahui manfaat dari bentonite sebagai media pembumian maka dilakukan pengujian dengan menggunakan metode tiga titik dan diukur dengan alat earth resistance tester dengan merubah media tanah dengan treatment yang telah ditentukan.

\section{BENTONITE SEBAGAI MEDIA PEMBUMIAN ELEKTRODA BATANG}

Sistem pembumian adalah suatu tindakan dasar yang sangat penting untuk menjamin keamanan dan keandalan dari operasi sistem tenaga listrik serta memastikan keselamatan manusia dari gangguan yang terjadi pada jaringan listrik dan peralatan. Dalam penerapannya tidak semua sistem jaringan listrik dihubungkan langsung dengan sistem pembumian. Sistem pembumian digunakan untuk menyalurkan arus ganguuan yang terjadi pada sistem kelistrikan seperti hubung singkat, petir, maupun arus bocor, sehingga sistem kelistrikan tersebut aman bagi peralatan maupun bagi manusia. Dalam sistem pembumian atau biasa disebut grounding system, jenis tanah sangat mempengaruhi baik atau buruk sistem tersebut. Hal ini dikarenakan tidak semua tanah memiliki nilai resistansi yang baik. Nilai resistansi pada tanah dipengaruhi oleh struktur dan kandungan dalam tanah tersebut. Selain itu, daerah dimana tanah itu berada juga mempengaruhi struktur dan kandungan tanah tersebut [6].

Tabel 1.

Nilai resistivitas beberapa jenis tanah [6]

\begin{tabular}{lc}
\hline \hline Jenis Tanah & Resistivitas dalam (ohm-cm) \\
\hline Tanah liat, tanah kebun, dll & $500-5.000$ \\
Tanah liat & $800-5.000$ \\
Campuran tanah liat, pasir dan kerikil & $4.000-25.000$ \\
Pasir dan kerikil & $6.000-10.000$ \\
Batu tulis, pasir berbatu, dll & $1.000-50.000$ \\
Batu karang & $20.000-1.000 .000$ \\
\hline \hline
\end{tabular}

Nilai resistivitas yang berada di dalam Tabel 1 adalah suatu perkiraan untuk nilai resistivitas yang diharapkan. Dalam pengujian pada penelitian ini menggunakan elektroda batang jenis elektroda batang. 


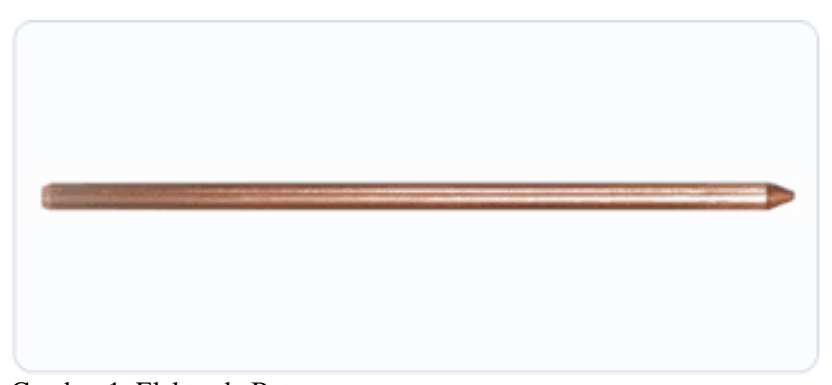

Gambar 1. Elektroda Batang

Gambar 1 merupakan gambar dari elektroda batang yang digunakan untuk alat pembantu mengukur resistansi tanah.

Elektroda batang biasanya terbuat dari batang atau pipa logam. Pada umumnya bahan yang bagus untuk pembuatan batang elektroda adalah tembaga murni. Selain itu perlu diperhatikan bahwa bahan untuk elektroda harus berbahan anti korosif.

Penggunaan elektroda batang yang ditancapkan tegak lurus dengan permukaan tanah pada sistem pembumian, jalur persebaran arus gangguan yang melewati elektroda tersebut dapat digambarkan sebagai setengah lingkaran bola. Jalannya arus yang melewati batang konduktor dapat dilihat pada Gambar 2.

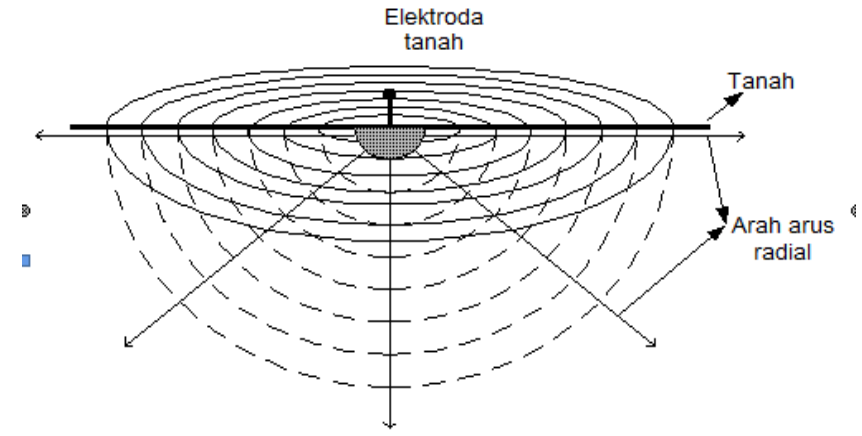

Gambar 2. sel-sel tanah sebagai elektroda pembumian

Aspek utama yang ditinjau dari penelitian ini adalah pengkondisian terhadap tanah yang dilakukan dengan menambahkan bentonite sebagai media tambahan untuk penurunan resistansi tanah. Bentonite adalah bahan pengurukan atau backfill yang meningkatkan konduktivitas tanah disekitar elektroda batang dan sistem pembumian. Pada umumnya bentonite digunakan pada kondisi dengan resistansi tinggi termasuk berbatu dan berpasir tanah, serta medan kering ,pegunungan, dan tanah beku agar resistansi menurun untuk menciptakan sistem pentanahan yang handal.

\section{PENGUJIAN DAN PENGAMBILAN DATA}

Metode penelitian pada penelitian ini adalah metode pengujian secara langsung yang mencakup antara lain, pengukuran resistansi bentonite, resistivitas bentonite, resistivitas tanah, resistivitas tanah dengan campuran bentonite (untuk pengujian dengan batang konduktor horizontal), pengukuran resistansi tanah sebelum pencampuran, dan pengukuran nilai resistansi tanah setelah pemberian treatment.

\section{A. Rangkaian Pengujian}

\section{Pengukuran Resistivitas Bentonite}

Untuk mengukur resistivitas dari bentonie, sebelumnya perlu dilakukan pengukuran resistansi dari bentonite itu sendiri. Setelah mengetahui nilai resistansi dari bentonite, maka dapat dihitung nilai resistivitas dari bahan tersebut.

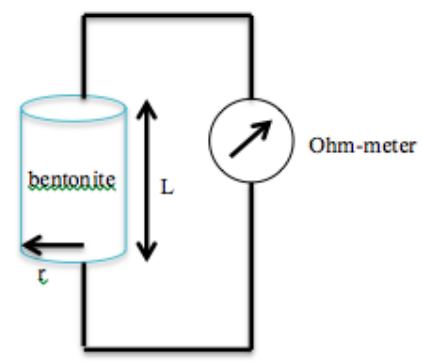

Gambar 3. Rangkaian Pengukuran Resistansi Bentonite

\section{Rangkaian Pengukuran Resistivitas Tanah}

Pada Rangkaian pengukuran resistivitas tanah dapat diketahui menggunakan empat buah elektroda batang yang dihubungkan dengan Earth Resistance Tester, seperti yang ditunjukkan dalam Gambar 4.

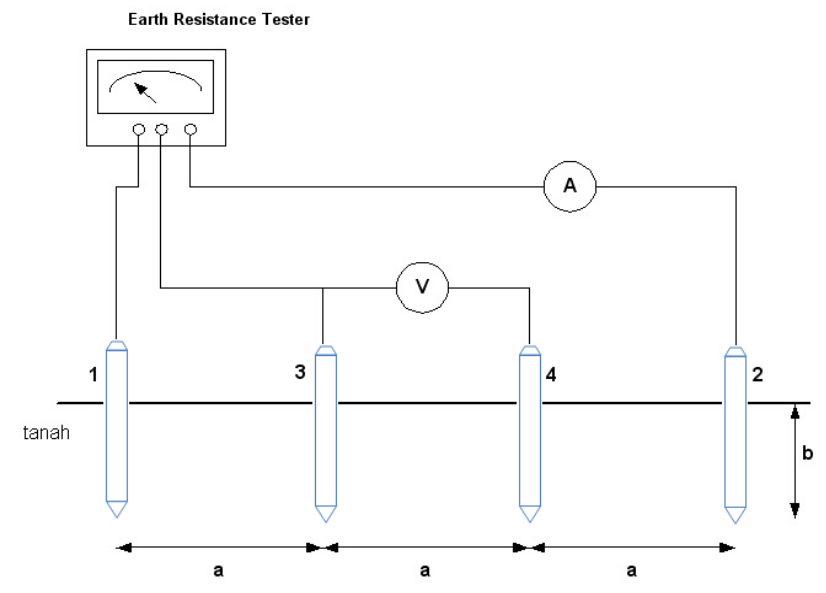

Gambar 4. Pengukuran resistivitas tanah menggunakan metode empat titik dengan Earth Resistance Tester

Earth Resistance Tester selain digunakan untuk mengukur nilai resistansi pembumian, dapat juga digunakan untuk menghasilkan sumber tegangan, yang dibutuhkan dalam pengukuran resistivitas tanah. Arus $I$ dapat mengalir dan dapat terbaca pada Ampermeter karena adanya lebih dari satu buah elektroda batang yang dimasukkan ke tanah sehingga membentuk loop tertutup, arus masuk ke tanah melalui salah satu buah elektroda batang dan kembali ke elektroda batang yang lain. Setelah itu dapat diketahui nilai tegangan dan arus yang terbaca pada masing-masing alat ukur Voltmeter dan Ampermeter.

\section{Rangkaian Pengukuran Resistansi Tanah}

Pengujian untuk mengetahui nilai resistansi tanah dilakukan dengan menggunakan alat earth resistance tester dan 
menggunakan metode tiga titik. Nilai resistansi tanah yang didapatkan adalah nilai resistansi yang diukur pada elektroda utama. Treatment yang nantinya dilakukan, akan diletakkan pada elektroda utama.

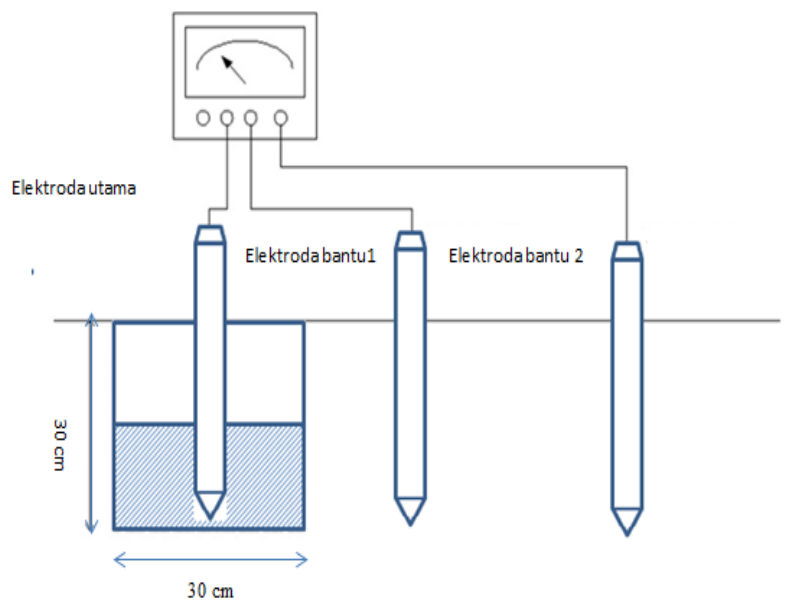

Gambar 5. Rangkaian pengukuran nilai resistansi tanah

Gambar 5 adalah rangkaian untuk mengukur nilai resistansi tanah setelah tanah tersebut diberi media tambahan berupa bentonite. Pada elektroda utama atau elektroda pengukuran, diletakkan treatment sesuai dengan treatment pengukuran yang diinginkan.

Peletakan bentonite sebagai treatment pada penurunan resistansi tanah dijelaskan pada gambar berikut :

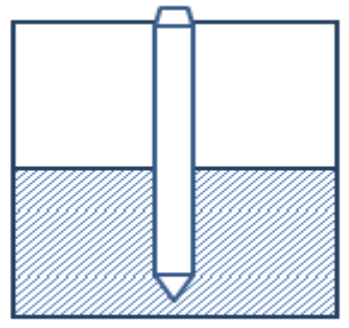

Rosisi 1

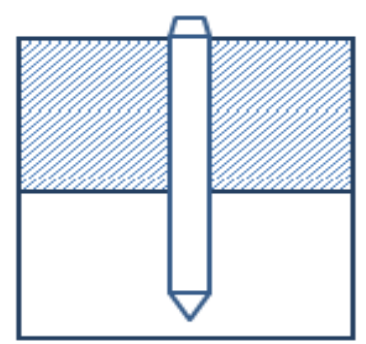

Posisi 2
Keterangan :

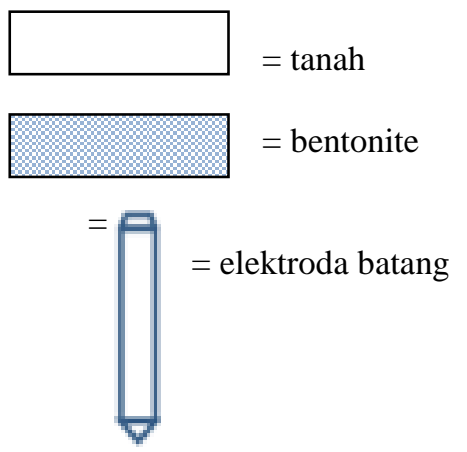

Gambar 6. Posisi peletakan bentointe untuk posisi 1 dan posisi 2

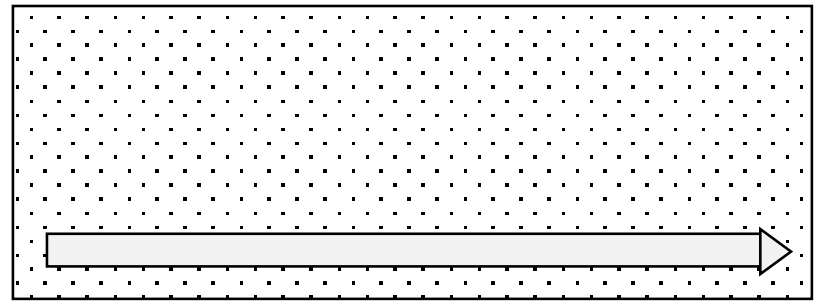

Gambar 7. Treatment pengujian posisi 3 (25\% bentonite)

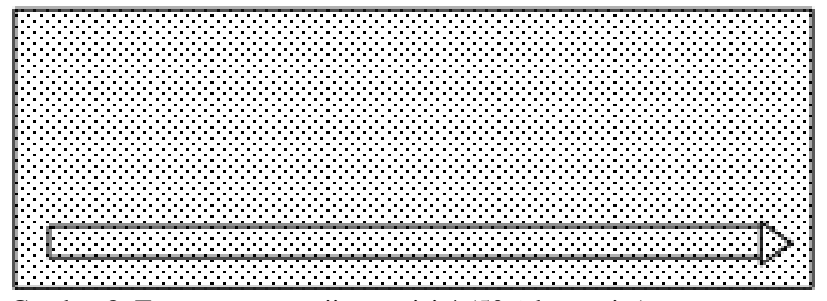

Gambar 8. Treatment pengujian posisi 4 (50\% bentonite)

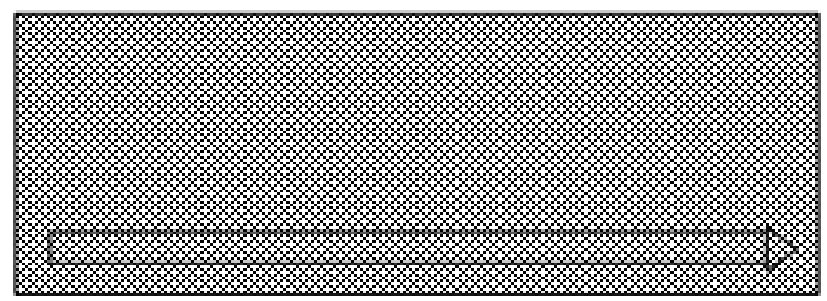

Gambar 9. Treatment pengujian posisi 5 (75\% bentonite)

Pada pengujian, posisi peletakan treatment terletak pada bagian elektroda utama. Setiap treatment akan diuji untuk mengetahui pengaruh peletakan bentonite terhadap penurunan nilai resistansi tanah.

\section{HASIL DAN ANALISIS}

Data - data yang ada dalam penelitian adalah data - data yang didapatkan dari hasil pengambilan data berupa pengukuran secara langsung baik di lapangan maupun di laboratorium. Sebelum melakukan pengambilan data tersebut perlu dilakukan pengujian tentang karakteristik sifat - sifat kelistrikan bentonite, sehingga dari pengujian tersebut dapat dianalisis:

1. Pengaruh peletakan bentonite di sekitar elektroda batang (rod).

2. Pengaruh volume bentonite yang seragam dengan beberapa model variasi peletakan bentonite terhadap nilai resistansi pembumian.

Berikut adalah hasil pengukuran secara langsung dengan menggunakan alat Earth resistance tester :

Tabel 2.

Hasil pengukuran resistansi pembumian

\begin{tabular}{lll}
\hline \hline Pengujian & Kondisi & $\mathbf{R}_{\mathbf{e}}(\mathbf{o h m})$ \\
\hline Batang Konduktor & normal & 9,34 \\
Vertikal & Posisi 1 & 7,41 \\
& Posisi 2 & 7,08 \\
Batang Konduktor & normal & 4,42 \\
Horizontal & Posisi 3 & 4,01 \\
& Posisi 4 & 3,32 \\
& Posisi 5 & 3,23 \\
\hline \hline
\end{tabular}


1. Pengukuran nilai resistivitas bentonite

Dengan menggunakan rangkaian pengukuran pada Gambar 3, maka dapat diperoleh perhitungan sebagai berikut:

Data-data untuk pengukuran resistivitas bentonite (posisi 1 dan posisi 2) :

$\mathrm{R}$ (resistansi bentonite) $\quad=80,4 \mathrm{ohm}$

1 (tinggi tabung pengujian) $=5 \mathrm{~cm}$

$\mathrm{r}$ (jari-jari tabung pengujian) $=2 \mathrm{~cm}$

$$
\rho \frac{\frac{\pi r^{\bar{c}} R}{i}}{\rho} \frac{(3.14)(2)^{2}(80.4)}{5}
$$

Jadi resistivitas dari bentonite untuk pengujian posisi 1 dan posisi 2 didapatkan senilai $201,96 \mathrm{ohm}-\mathrm{cm}$

Data-data untuk pengukuran resistivitas (posisi 3, 4 dan 5) :

$\mathrm{R}_{3}$ (resistansi posisi 3) $=0,31 \mathrm{k} \mathrm{ohm}$

$\mathrm{R}_{4}$ (resistansi posisi 4 ) $\quad=0,23 \mathrm{k} \mathrm{ohm}$

$\mathrm{R}_{5}$ (resistansi posisi 5) $=0,18 \mathrm{k} \mathrm{ohm}$

1 (tinggi tabung pengujian) $=5 \mathrm{~cm}$

$\mathrm{r}$ (jari-jari tabung pengujian) $=2 \mathrm{~cm}$

$$
\begin{aligned}
& \rho_{3} \frac{\pi r^{\bar{c}} R}{i} \\
& \rho_{3} \frac{(3.14)(2)^{2}(0,30)\left(10^{3}\right)}{5} \\
& \rho_{3} \quad 753.6 \mathrm{chm} \mathrm{cm} \\
& \rho_{4} \frac{\pi r^{i} R}{i} \\
& \rho_{4} \frac{(3.14)(2) 2(0,23)\left(10^{5}\right)}{5} \\
& \rho_{4} \quad 577.7 \text { onm on } \\
& \rho_{5} \frac{\pi r^{i} R}{i} \\
& \rho_{5} \frac{(3.14)(2)-(0,18)\left(10^{3}\right)}{5} \\
& \rho_{5} \quad 452.16 \text { aim } \mathrm{cm}
\end{aligned}
$$

Jadi resistivitas yang didapatkan dari perhitungan bernilai sebagai berikut :

$$
\begin{array}{lll}
\rho_{3} & 753.6 \text { ohm } & \text { an } \\
\rho_{4} & 577.7 \text { onm } & \text { an } \\
\rho_{3} & 452.16 \text { oim } & \mathrm{cm}
\end{array}
$$

2. Pengukuran nilai resistivitas tanah

Dengan menggunakan rangkaian pada Gambar 4. dapat dihitung nilai resistivitas dari tanah, perhitungannya adalah sebagai berikut :

Data perhitungan resistivitas tanah antara lain:

a (jarak antar elektroda batang) $\quad=500 \mathrm{~cm}$

$\mathrm{b}$ (kedalaman elektroda batang) $\quad=30 \mathrm{~cm}$

$\mathrm{U}$ (tegangan terukur pada volt-meter) $\quad=0,02 \mathrm{~V}$

$\mathrm{I}$ (arus terukur pada ampere-meter) $\quad=0,06 \mathrm{~A}$

Dengan menggunakan persamaan (3-1), maka dapat diperoleh nilai resistivitas sebagai berikut:

$$
\begin{aligned}
& \rho=\frac{4 \pi u \nu}{\left(1+\frac{2 a}{\sqrt{\left(u^{2}+4 b^{2}\right)}}-\frac{2 u}{\sqrt{\left(4 a^{2}+4 j^{2}\right)}}\right) I} \\
& \rho=\frac{4(3,14)(500)(0,02)}{\left(1+\frac{2(500)}{\sqrt{500^{2}-4(30)^{2}}}-\frac{2(500)}{\sqrt{4(500)^{2}+4(30)^{2}}}\right) 0,06} \\
& \rho=1051,92 \text { uhm }-c m
\end{aligned}
$$

maka nilai resistivitas tanah adalah sebesar 1051,92 ohm-cm

Setelah didapatkan data-data yang diperlukan, maka perhitungan matematis untuk nilai resistansi pembumian dari tiap treatment pengukuran dapat dilakukan.

a. Model Peletakan Posisi 1

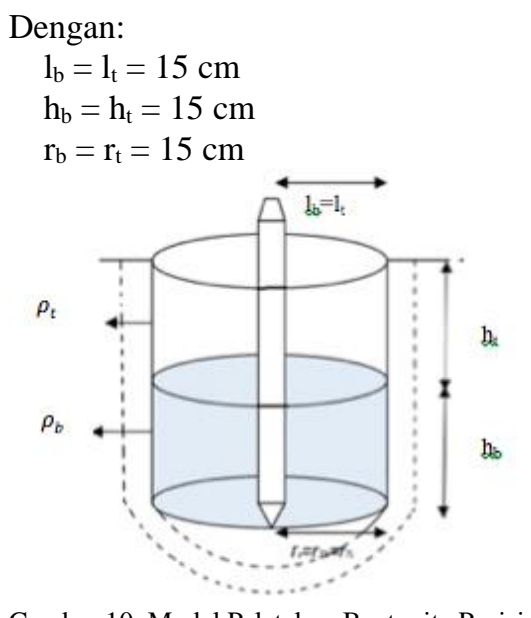

Gambar 10. Model Peletakan Bentonite Posisi 1

maka,

$$
\begin{aligned}
& R_{b} \frac{(201,96)(15)}{(2)(3,14)(15)(15)} \quad 2,14 \text { ohms } \\
& \text { R. } \frac{(1051,92)(15)}{(2)(3.14)(15)(1 \mathrm{j})} \quad 11,16 \mathrm{am} \\
& R_{t b} \frac{(1051,92)(15)}{(2)(3,14)\left(15^{2}\right)} \quad 11,16 \text { ohu } \\
& R_{t:} \quad R_{b} / / R_{t} / / R_{\gamma b} \quad 1,54 \% h n
\end{aligned}
$$

Berdasarkan Gambar 10 hasil perhitungan nilai resistansi pembumian untuk tiap lapisan bagian atas saja. Untuk mengetahui nilai resistansi tanah keseluruhan maka diperlukan hasil iterasinya. Berdasarkan hasil iterasi, nilai resitansi tanah yang didapatkan sebesar 7,4283 ohm.

\section{b. Model Peletakan Posisi 2}

$$
\begin{aligned}
& \text { Dengan: } \\
& \mathrm{l}_{\mathrm{b}}=\mathrm{l}_{\mathrm{t}}=15 \mathrm{~cm} \\
& \mathrm{~h}_{\mathrm{b}}=\mathrm{h}_{\mathrm{t}}=15 \mathrm{~cm} \\
& \mathrm{r}_{\mathrm{b}}=\mathrm{r}_{\mathrm{t}}=15 \mathrm{~cm}
\end{aligned}
$$




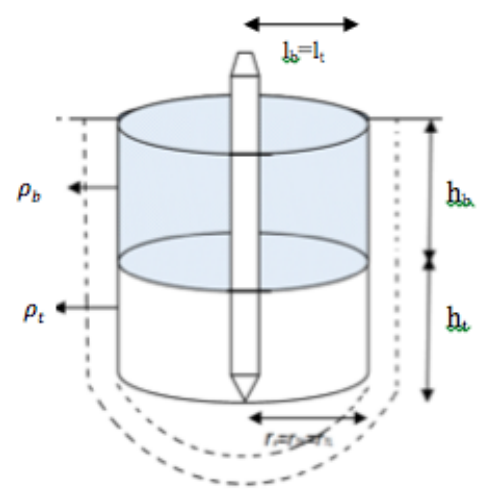

Gambar 11. Model Peletakan Bentonite Posisi 2

maka,
$R_{b} \frac{(201,96)(15)}{(2)(3,14)(15)(15)} \quad 2,14$ ohm
R: $\frac{(1051,92)(15)}{(2)(3.14)(15)(15)} 11,16 \mathrm{omm}$
$R_{t b} \frac{(1051,92)(15)}{(2)(3,14)\left(15^{2}\right)} \quad 11,16 \mathrm{ohm}$
R.: $R_{\mathrm{b}} / / R_{+} / / R_{r \mathrm{~b}} \quad 1, \mathrm{j} 4$ ohn

Berdasarkan Gambar 11. hasil perhitungan nilai resistansi pembumian untuk tiap lapisan bagian atas saja. Untuk mengetahui nilai resistansi tanah keseluruhan maka diperlukan hasil iterasinya. Berdasarkan hasil iterasi, nilai resitansi tanah yang didapatkan sebesar 7,1005 ohm.

c. Model Peletakan Bentonite Posisi 3

$$
\begin{array}{ll}
\text { Dengan : } & \\
\mathrm{h} \text { (kedalaman tanah) } & =30 \mathrm{~cm} \\
\mathrm{p} \text { (panjang) } & =150 \mathrm{~cm} \\
1 \text { (lebar) } & =30 \mathrm{~cm}
\end{array}
$$

$\rho_{3}($ resistivitas posisi 3$)=753,6 \mathrm{ohm}-\mathrm{cm}$

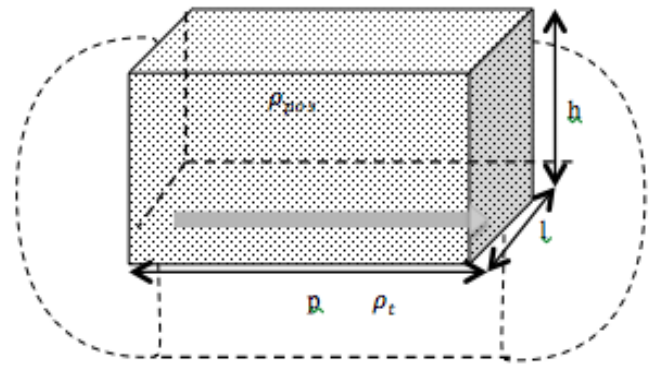

Gambar 12. Model Peletakan Bentonite Posisi 3

maka,

$$
\begin{aligned}
& R_{\text {tas }} \frac{(753,6)(30)}{(3.14)(30)(150)} \quad 1,6 \mathrm{okm} \\
& R_{t b} \frac{(1051,92)(30)}{(3.14)(30)(150)} \quad 2,23 \mathrm{ohm} \\
& R_{\text {si }} \frac{(1051,92)(30)}{(2)(3.14)(30)^{2}} \quad 5,58 \mathrm{am} \\
& \mathrm{R}_{\mathrm{N}}=\mathrm{Rta3} / / \mathrm{Rtb} / / \mathrm{Rsb} / / \mathrm{Rsb}=0,698 \mathrm{ohm}
\end{aligned}
$$

Berdasarkan Gambar 12. hasil perhitungan adalah nilai resistansi pembumian untuk setiap lapis. Setelah dilakukan iterasi, nilai resistansi tanah keseluruhan yang didapatkan adalah sebesar 4,01 ohm.

\section{d. Model Peletakan Bentonite Posisi 4}

$$
\begin{array}{ll}
\text { Dengan : } & \\
\mathrm{h}(\text { kedalaman tanah) } & =30 \mathrm{~cm} \\
\mathrm{p}(\text { panjang }) & =150 \mathrm{~cm} \\
1 \text { (lebar) } & =30 \mathrm{~cm} \\
\rho_{4}(\text { resistivitas posisi } 4) & =577,7 \mathrm{ohm}-\mathrm{cm}
\end{array}
$$

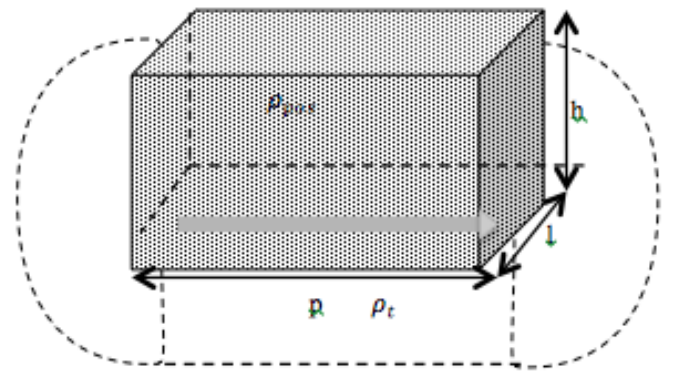

Gambar 13. Model Peletakan Bentonite Posisi 4

$$
\begin{aligned}
& \text { maka, } \\
& R_{\text {:ac }} \frac{(577,7)(30)}{(3.14)(30)(150)} \quad 1,226 \mathrm{okm} \\
& R_{: b} \frac{(1051,92)(30)}{(3.14)(30)(150)} \quad 2,23 \mathrm{ohm} \\
& R_{: s i} \frac{(1051,92)(30)}{(2)(3,14)(30)^{2}} \quad 5,58 \mathrm{omm} \\
& R_{N}=\mathrm{Rta} 3 / / \mathrm{Rtb} / \mathrm{Rsb} / / \mathrm{Rsb}=0,616 \mathrm{ohm}
\end{aligned}
$$

Berdasarkan Gambar 13. hasil perhitungan adalah nilai resistansi pembumian untuk setiap lapis. Setelah dilakukan iterasi, nilai resistansi tanah keseluruhan yang didapatkan adalah sebesar 3,3214 ohm.

\section{e. Model Peletakan Bentonite Posisi 5}

$$
\begin{array}{ll}
\text { Dengan : } & \\
\mathrm{h} \text { (kedalaman tanah) } & =30 \mathrm{~cm} \\
\mathrm{p} \text { (panjang) } & =150 \mathrm{~cm} \\
\mathrm{l} \text { (lebar) } & =30 \mathrm{~cm}
\end{array}
$$

$\rho_{5}($ resistivitas posisi 5$)=452,16 \mathrm{ohm}-\mathrm{cm}$

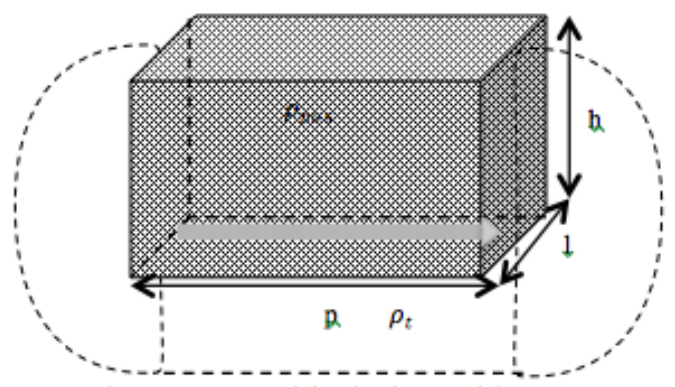

Gambar 14. Model Peletakan Bentonite Posisi 5 
maka,

$$
\begin{aligned}
& R_{\text {tas }} \frac{(j 77.7)(30)}{(3.14)(30)(150)} \quad 0.96 \mathrm{ohm} \\
& R_{\mathrm{bb}} \frac{(1051,92)(30)}{(3.14)(30)(150)} \quad 2,23 \mathrm{omm} \\
& R_{s, w} \frac{(1051,92)(30)}{(2)(3,14)(30)^{2}} \quad 5,58 \mathrm{am} \\
& \mathrm{R}_{\mathrm{N}}=\mathrm{Rta} 3 / / \mathrm{Rtb} / / \mathrm{Rsb} / / \mathrm{Rsb}=0,541 \mathrm{ohm}
\end{aligned}
$$

Berdasarkan Gambar 14. hasil perhitungan adalah nilai resistansi pembumian untuk setiap lapis. Setelah dilakukan iterasi, nilai resistansi tanah keseluruhan yang didapatkan adalah sebesar 3,2320 ohm.

\section{KESIMPULAN}

Beberapa kesimpulan yang dapat diperoleh dari studi tentang pemanfaatan bentonite sebagai media pembumian elektroda batang adalah sebagai berikut :

1. Peletakan bentonite pada media pentanahan berpengaruh tidak terlalu besar pada penurunan nilai resistansi pentanahan. Untuk pengukuran nilai resistansi pentanahan menggunakan batang konduktor secara vertikal, posisi peletakan yang terbaik adalah posisi 2 dngan hasil pengukuran secara langsung sebesar 7,08 ohm dan hasil analisis matematis sebesar $7,1005 \mathrm{ohm}$ dari nilai resistansi awal sebelum pemberian bentonite sebesar $9,34 \mathrm{ohm}$.

2. Nilai rata-rata penurunan resistansi pentanahan dengan penambahan bentonite baik untuk penanaman batang konduktor secara vertikal maupun horizontal adalah sekitar $1,725 \mathrm{ohm}$.

3. Nilai resistansi pentanahan dengan menggunakan batang konduktor horizontal bernilai lebih baik dibandingkan sistem pentanahan dengan menggunakan batang konduktor secara vertikal dikareanakan luas permukaan batang konduktor di dalam tanah lebih besar sehingga persebaran medan dari batang konduktor dapat tersebar dengan baik. Hal ini dibuktikan dengan hasil pengukuran resistansi tanah awal yang bernilai $4,42 \mathrm{ohm}$ untuk batang horizontal dan 9,34 untuk penggunaan batang vertikal.

4. Kerapatan material di dalam tanah menentukan baik tidaknya resistansi pentanahan.

\section{DAFTAR PUSTAKA}

[1] W,Keitz ,Switzer. 1999 .Practical Guide to Elecktrical grounding.

[2] Hutauruk, T.S. 1991. Pembumian Netral Sistem Tenaga dan Pembumian Peralatan. Jakarta: Erlangga.

[3] 1982. IEEE Green Book: Recommended Practice For Grounding of Industrial and Commercial Power Sistem ANSI. New York: Institute of Electrical and Electronics Engineers, Inc.

[4] George ,Frank, Tagg.1964.Earth Resistances. Pitman Publishing Corp.

[5] Yanuarianto, Yudistiro.2008.Pemanfaatan Arang Kayu Sebagai Media Pembumian Elekroda Jenis Batang.Malang : Jurusan Teknik Elektro Fakultas Teknik Universitas Brawijaya.

[6] Tagg, G.F. 1964. Earth Resistance. London: The Whitefriars Press Ltd. 